\title{
Fire Induced Flow under a Sloped Ceiling
}

\author{
HSIANG-CHENG KUNG, ROBERT D. SPAULDING and \\ PARASKEVAS STAVRIANIDIS \\ Factory Mutual Research Corporation \\ 1151 Boston--Providence Turnpike \\ Norwood, Massachusetts 02062, USA
}

\section{ABSTRACT}

A series of fire tests was conducted under a smooth ceiling to investigate the ceiling gas flow as affected by ceiling slope, convective heat release rate of the fire and clearance between the fuel top surface and the ceiling. Besides a horizontal ceiling reference, three ceiling slopes were investigated: $10^{\circ}, 20^{\circ}$ and $30^{\circ}$. Pool fires were used as fire sources. Two pool diameters, two different fuels (heptane and methanol) and three ceiling clearances were used. In each test, measurements were made of ceiling gas temperatures, ceiling gas velocities, and fuel mass loss. Empirical correlations for the near-maximum gas velocity and excess temperature of the ceiling flow along the steepest run were established in terms of ceiling slope, radius from the point of intersection of the ceiling with the pool centerline, and characteristics of the undeflected plume at the ceiling level. The ceiling slope had a more pronounced effect on velocity variation along the steepest run than on temperature variation. In the upward direction, the rate of velocity decrease with radius was reduced significantly as the ceiling slope increased. In the downward direction, at a certain distance from the pool centerline, the flow separated from the ceiling and turned upward. The larger the ceiling slope, the sooner the turning occurred. Furthermore, the rate at which gas temperature approached ambient in the downward direction increased with ceiling slope, while the temperature decrease in the upward direction was not much affected by change of ceiling slope.

KEYWORDS: Fire Plume, Celling Flow, Sprinkler Response, Sloped Ceiling.

\section{INTRODUCTION}

Sprinkler systems have played a major role in reducing industrial fire losses. In order to design effective sprinkler protection, we need to know the fire size at sprinkler actuation. To predict sprinkler response, knowledge of ceiling flow velocity and gas temperature is required.

For several years, correlations of experimental data have been available which make it possible to predict temperatures and velocities generated by fire under a smooth horizontal ceiling. Such correlations are available for both steady fires [1] and fires growing with the second power of time from 
ignition [2]. However, the correlations are limited to fires with low flame reach compared to the ceiling height.

Knowledge of ceiling flow induced by strong fire plume is required for sprinkler response prediction, since at sprinkler actuation flames have already impinged on the ceiling in most situations. Steady-state ceiling flows produced by strong fire plumes from propane burners, impinging on smooth horizontal ceilings, have been investigated by Heskestad and Hamada [3]. The ceiling gas temperature data were correlated successfully with the radius from the fire axis in a nondimensional form for those fires which produce flame heights ranging up to twice the ceiling clearance. The excess ceiling gas temperature (relative to ambient) was nondimensionalized with the centerline excess temperature in the undeflected fire plume at the ceiling level; the radius from the fire axis was nondimensionalized with the characteristic width of the undeflected plume at the ceiling level. A series of freeburn tests was conducted by Kung et al [4] to investigate the flows under a large horizontal ceiling induced by growing rack storage fires. Empirical correlations for the near-maximum gas velocity and excess temperature of the ceiling flows were established in terms of radius from the fire axis and characteristics of the undeflected plume at the ceiling level in the same fashion. In developing these correlations, the guasisteady approximation was applied to the growing rack storage fires.

Buildings with sloped ceiling construction are common. Experimental data of fire induced ceiling flows in this kind of building are scarce; a method to predict response of sprinkler and detector under a sloped celling is not yet available. This paper presents an experimental study on flows under sloped ceilings induced by constant neat-release-rate fires. Pool fires were used to provide the constant heat-release-rate fire sources. The effects of ceiling slope, heat release rate of the fire and clearance between the ceiling and the pool surface have been investigated. Correlations of the near-maximum ceiling-gas excess temperature and velocity along the steepest run passing through the ceiling center which intercepted with the fuel pool centerline have been established in terms of radius from the ceiling center. These correlations can be used to provide near-maximum ceiling gas temperature and velocity along this run for the purpose of predicting sprinkler and detector response.

\section{EXPERIMENTS}

A series of pool fire tests was conducted under a smooth ceiling to investigate the ceiling gas flow as affected by ceiling slope, $\theta$, heat release rate of the pool fire and clearance between the pool surface and the ceiling. Besides a horizontal ceiling reference, three ceiling slopes were investigated: $10^{\circ}, 20^{\circ}$ and $30^{\circ}$. Two pool diameters, $0.150 \mathrm{~m}$ and $0.228 \mathrm{~m}$, were selected, and two different fuels, methanol and heptane, were employed. The distance along the vertical centerline of the fuel pool from the initial pool surface to the point where the centerline intercepts with the ceiling is called the ceiling clearance, $h$. Three ceiling clearances: $0.279 \mathrm{~m}$, $0.584 \mathrm{~m}$, and $0.889 \mathrm{~m}$ were used. The combinations of test variables are presented in Table $I$.

The fuel pool was burned under a test ceiling which was placed beneath a large laboratory smoke hood $(6.7 \mathrm{~m} \times 5.5 \mathrm{~m}$ with an outside parameter depth of $0.31 \mathrm{~m}$ ). The smoke hood was located in a laboratory measuring $14.6 \mathrm{~m}$ long $\times 8.5 \mathrm{~m}$ wide $\times 3.7 \mathrm{~m}$ high. Figure 1 illustrates the overall test arrangement, sketched to scale. The fuel pool rested on a load platform 


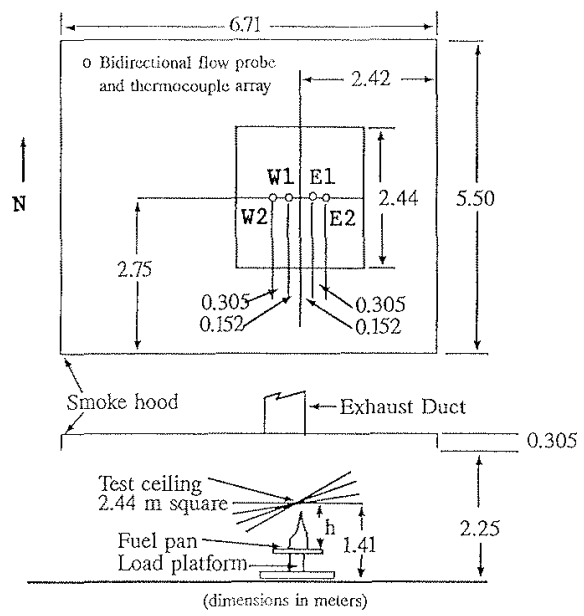

Figure 1. Experimental setup and instrumentation layout.

system (GSE Model 4840, Farmington Hills, Michigan; accuracy: 0.5 grams) for mass loss measurement. For the largest ceiling clearance, the load platform system rested directly on the floor; for smaller ceiling clearances, the system was elevated by wood platforms accordingly. Directly above the fuel pool, a $2.44 \mathrm{~m} \times 2.44 \mathrm{~m}$ test ceiling was supported at the four corners of the celling by a steel channel structure. The celling was constructed from $12.7 \mathrm{~mm}$ thick Marinite I boards bolted to a frame of steel channels. The slope of the ceiling was set at a preselected slope by adjusting the supports at the four ceiling corners.

The fuel pool was contained in one of the two circular pans $(0.150 \mathrm{~m}$ and $0.228 \mathrm{~m}$ inside diameters) made from $1.27 \mathrm{~mm}$ thick aluminum sheets. The depth of the pans was $49.5 \mathrm{~mm}$. The bottom radii of the pans were $9.4 \mathrm{~mm}$ and $12.7 \mathrm{~mm}$ for the $0.150 \mathrm{~m}$ and $0.228 \mathrm{~m}$ diameter pans, respectively. When heptane was used, water was placed into the pans to a level of $33 \mathrm{~mm}$ and then heptane added until the level of fuel and water was $41 \mathrm{~mm}$. For methanol fire tests, the pan was filled with methanol to a depth of $41 \mathrm{~mm}$.

The layout of ceiling instrumentation is also shown in Figure 1 . Ceiling gas temperatures and velocities were measured at four locations along the east-west run passing through the celling center. The four locations were labeled E1, E2, W1 and $W 2$ as shown in Figure 1. At each of Locations E1, E2 and $W 1$, four thermocouples were installed at 13, 25, 38 and $51 \mathrm{~mm}$ below the ceiling to measure gas temperature profile. At Location w2 three thermocouples were installed at 13,38 , and $64 \mathrm{~mm}$ below the celling. All thermocouples were fabricated from 30 gage $(0.25 \mathrm{~mm}$ diameter) inconel sheathed, chromel-alumel thermocouple wire. The thermocouple beads were 0.7 $\mathrm{mm}$ in diameter. At each of the four locations, a bidirectional pressure flow probe [5] was located at $38 \mathrm{~mm}$ below the ceiling with the probe axis pointing toward the centerline of the ceiling to measure the gas velocity. The probes were $12.7 \mathrm{~mm}$ in diameter and $25.4 \mathrm{~mm}$ long. Each probe was connected to an individual electronic manometer (Datametrics Model 1173 Barocell Electronic Manometer) to measure differential pressures. With this system, it was possible to measure velocities reliably down to $0.3 \mathrm{~m} / \mathrm{s}$. 
Data from the instrumentation were acquired using a MINC 11 Computer System (Digital Equipment Corporation). Signals from the chromel-alumel thermocouples were filtered at $3 \mathrm{~Hz}$ using signal conditioners (Analog Devices, Norwood, MA). Data were acquired at a rate of one scan per second.

During each test, forced ventilation in the laboratory was shut down and all doors communicating with the test volume were closed. Thirty seconds before ignition, the computer started to collect pretest data. Duration of each test was at least five minutes, although a steady burning rate was usually reached within one minute.

\section{DATA ANALYSIS AND RESULTS}

In this study only time-averaged values of gas temperatures and velocities of the flow under the ceiling were investigated. The data were averaged over a $60 \mathrm{~s}$ steady burning interval during which the measured gas temperatures and velocities were reasonably steady. The period of fluctuation due to large-scale eddies was roughly 3 to $4 \mathrm{~s}$. The selected time interval of data averaging for each test is listed in Table 1.

For each test, the burning rate during the period of investigation was derived from the weight loss data of the fuel pool, applying the linearleast-square fit method to the data. Tewarson reported [6] that the measured heats of combustion of heptane and methanol pool fires $(0.102 \mathrm{~m}$ diameter) were 41 and $19.5 \mathrm{~kJ} / \mathrm{g}$, respectively, whereas their respective convective fractions of the total heat release rate were 0.64 and 0.88 . Kung and Stavrianidis [7] reported similar values for large pool fires (1.22 $m$ diameter) of methanol and heptane. The convective heat release rate, $Q_{c}$, of the fire was obtained by multiplying the burning rate with the heat of combustion and the convective fraction. Both the burning rate and the convective heat release rate of all the tests are presented in Table 1.

\section{Characteristics of Undeflected Plume}

In this study, the near-maximum velocity, $u_{m}$, and excess temperature, $\Delta T_{m}$, in the ceiling gas flow were nondimensionalized with the centerline velocity and excess temperature of the undeflected fire plume at the ceiling level where the pool centerline would have intercepted with the ceiling, respectively. The radius, $r$, from the celling center was nondimensionalized with the characteristic width of the undeflected plume at the ceiling level. The plume laws $[7,8]$ provide expressions for plume centerline excess temperature, $\Delta \mathrm{T}_{\mathrm{c}}$, and velocity, $\mathrm{w}_{\mathrm{c}}$ :

$$
\begin{aligned}
& \Delta \bar{T}_{c}=\Delta T_{c} / T_{a}=A g^{-1 / 3}\left(C_{p} \rho_{a} T_{a}\right)^{-2 / 3} Q_{c}^{2 / 3}\left(z-z_{o}\right)^{-5 / 3} \\
& w_{c}=B g^{1 / 3}\left(C_{p} \rho_{a} T_{a}\right)^{1 / 3} Q_{c}^{1 / 3}\left(z-z_{o}\right)^{1 / 3}
\end{aligned}
$$

where $C_{p}$ is the specific heat of the plume gases (essentially air); $T_{a}$ and $\rho_{\mathrm{a}}$ are ambient temperature and density, respectively; $z$ is the plume height above the initial surface of the fuel pool; and $z_{0}$ is the virtual origin location relative to the initial pool surface.

In order to determine the proportionality constants, $A$ and $B$, and the virtual origin location in Eqs. (1) and (2) for the pool fires investigated 
TABLE 1. TEST VARIABLES, BURNING RATES AND CONVECTIVE HEAT RELEASE RATES

\begin{tabular}{|c|c|c|c|c|c|c|c|}
\hline $\begin{array}{c}\text { Test } \\
\text { No. }\end{array}$ & Fuel & $\begin{array}{c}\text { Pan } \\
\text { Diam. } \\
(\mathrm{m}) \\
\end{array}$ & $\begin{array}{l}\text { Ceiling } \\
\text { Slope } \\
\text { (deg.) } \\
\end{array}$ & $\begin{array}{c}\text { Ceiling } \\
\text { Clearance } \\
(\mathrm{m}) \\
\end{array}$ & $\begin{array}{l}\text { Time }^{c} \\
\text { Interval } \\
\text { (sec) } \\
\end{array}$ & $\begin{array}{c}\text { Burning } \\
\text { Rate } \\
(\mathrm{g} / \mathrm{sec}) \\
\end{array}$ & $\begin{array}{l}\text { Convective } \\
\text { Heat Release } \\
\text { Rate (kW) } \\
\end{array}$ \\
\hline $\mathrm{H} 1$ & $\mathrm{H}^{\mathrm{a}}$ & 0.150 & 0 & 0.889 & $220-280$ & 0.167 & 4.25 \\
\hline $\mathrm{H}_{2}$ & $\mathrm{H}$ & 0.150 & 0 & 0.584 & $120-180$ & 0.163 & 4.15 \\
\hline $\mathrm{H} 3$ & $\mathrm{H}$ & 0.228 & 0 & 0.889 & $195-255$ & 0.517 & 13.15 \\
\hline $1 H^{4}$ & $\mathrm{H}$ & 0.228 & 0 & 0.889 & $220-280$ & 0.516 & 13.13 \\
\hline $\mathrm{H} 5$ & $\mathrm{H}_{\mathrm{k}}$ & 0.228 & 0 & 0.584 & $150-210$ & 0.510 & 12.97 \\
\hline$M 1$ & $M^{B}$ & 0.150 & 0 & 0.889 & $130-190$ & 0.183 & 3.13 \\
\hline$M 2$ & M & 0.150 & 0 & 0.584 & $120-180$ & 0.186 & 3.18 \\
\hline M3 & M & 0.150 & 0 & 0.279 & $150-210$ & 0.178 & 3.04 \\
\hline M4 & M & 0.228 & 0 & 0.889 & $60-120$ & 0.467 & 7.99 \\
\hline M5 & M & 0.228 & 0 & 0.584 & $70-130$ & 0.539 & 9.22 \\
\hline M6 & M & 0.228 & 0 & 0.279 & $120-180$ & 0.442 & 7.56 \\
\hline HS1 & $\mathrm{H}$ & 0.150 & 10 & 0.889 & $120-180$ & 0.177 & 4.50 \\
\hline HS2 & $\mathrm{H}$ & 0.150 & 10 & 0.889 & $150-210$ & 0.183 & 4.66 \\
\hline HS3 & $\mathrm{H}$ & 0.150 & 10 & 0.584 & $120-180$ & 0.167 & 4.25 \\
\hline HSH & $\mathrm{H}$ & 0.228 & 10 & 0.889 & $140-200$ & 0.502 & 12.77 \\
\hline HS5 & $\mathrm{H}$ & 0.228 & 10 & 0.584 & $150-210$ & 0.512 & 13.03 \\
\hline MS 1 & M & 0.150 & 10 & 0.889 & $120-180$ & 0.180 & 3.08 \\
\hline MS2 & $M$ & 0.150 & 10 & 0.584 & $170-240$ & 0.186 & 3.18 \\
\hline MS3 & M & 0.150 & 10 & 0.279 & $120-180$ & 0.182 & 3.11 \\
\hline MS4 & M & 0.228 & 10 & 0.889 & $40-100$ & 0.473 & 8.09 \\
\hline MS5 & M & 0.228 & 10 & 0.584 & $160-220$ & 0.432 & 7.39 \\
\hline MS6 & M & 0.228 & 10 & 0.279 & $120-180$ & 0.485 & 8.29 \\
\hline $\mathrm{HTH}$ & $\mathrm{H}$ & 0.150 & 20 & 0.889 & $100-160$ & 0.174 & 4.43 \\
\hline $\mathrm{HT} 2$ & $\mathrm{H}$ & 0.150 & 20 & 0.584 & $120-180$ & 0.180 & 4.58 \\
\hline HT3 & $\mathrm{H}$ & 0.228 & 20 & 0.889 & $130-190$ & 0.529 & 13.46 \\
\hline $\mathrm{HT}_{4}$ & $\mathrm{H}$ & 0.228 & 20 & 0.584 & $90-150$ & 0.518 & 13.18 \\
\hline MT1 & M & 0.150 & 20 & 0.889 & $100-160$ & 0.183 & 3.13 \\
\hline MT2 & $M$ & 0.150 & 20 & 0.584 & $150-210$ & 0.186 & 3.18 \\
\hline MT3 & M & 0.150 & 20 & 0.279 & $140-200$ & 0.180 & 3.08 \\
\hline MT4 & M & 0.228 & 20 & 0.889 & $100-160$ & 0.469 & 8.02 \\
\hline MT5 & M & 0.228 & 20 & 0.584 & $200-260$ & 0.523 & 8.94 \\
\hline MT6 & $M$ & 0.228 & 20 & 0.279 & $100-160$ & 0.455 & 7.78 \\
\hline HP1 & $\mathrm{H}$ & 0.150 & 30 & 0.889 & $130-190$ & 0.174 & 4.43 \\
\hline HP2 & $\mathrm{H}$ & 0.150 & 30 & 0.584 & $140-200$ & 0.177 & 4.50 \\
\hline HP3 & $\mathrm{H}$ & 0.228 & 30 & 0.889 & $80-140$ & 0.521 & 13.25 \\
\hline $\mathrm{HP} 4$ & $\mathrm{H}$ & 0.228 & 30 & 0.584 & $160-220$ & 0.519 & 13.18 \\
\hline MP1 & M & 0.150 & 30 & 0.889 & $130-190$ & 0.193 & 3.30 \\
\hline MP2 & M & 0.150 & 30 & 0.584 & $80-140$ & 0.169 & 2.89 \\
\hline MP3 & M & 0.150 & 30 & 0.279 & $120-180$ & 0.187 & 3.20 \\
\hline MP4 & M & 0.228 & 30 & 0.889 & $130-190$ & 0.498 & 8.52 \\
\hline MP5 & M & 0.228 & 30 & 0.584 & $120-180$ & 0.513 & 8.77 \\
\hline MP6 & M & 0.228 & 30 & 0.279 & $90-150$ & 0.500 & 8.55 \\
\hline
\end{tabular}


in this study, a separate series of pool fire tests was conducted without the presence of the ceiling. In that test series, the same two fuel pans used in the experiments under a ceiling were used, and heptane and methanol were used as fuel. In each test, the centerline plume temperatures were measured at $0.241,0.546$ and $0.851 \mathrm{~m}$ above the initial pool surface, and the centerline velocities were measured at $0.279,0.584$ and $0.889 \mathrm{~m}$ above the surface. The weight loss of the fuel pool was also monitored to obtain the convective heat release rate of the fire.

Eq. (1) can be rearranged as:

$z=S\left(\Delta \bar{T}_{c} / Q_{c}^{2 / 3}\right)^{-3 / 5}+z_{o} \quad,\left[S=A^{3 / 5} g^{-1 / 5}\left(C_{p} \rho_{a} T_{a}\right)^{-2 / 5}\right]$

For each test, $z$ was plotted against $\left\{\Delta \overline{\mathrm{T}} / Q^{2 / 3}\right\}^{-3 / 5}$, and a straight line was fitted through the range of data which followed a linear trend. The average value of the slopes of the fitted lines was $0.192 \mathrm{~m} / \mathrm{kW}^{2} 5$. The constant A in Eq. (1) was determined from this averaged slope and $A=7.4$. Assigning $S$ with the value of 0.192 , Eq. (3) was used to fit the data of each test to obtain the virtual origin location for the test. For heptane fires, the virtual origin locations, $z_{0}$, were 0.11 and $0.13 \mathrm{~m}$ above the initial pool surface for the $0.150 \mathrm{~m}$ and $0.230 \mathrm{~m}$ diameter pans, respectively. For methanol fires, the values of $z_{0}$ were -0.05 and $-0.07 \mathrm{~m}$ for the $0.150 \mathrm{~m}$ and $0.230 \mathrm{~m}$ diameter pans, respectively.

A parameter, $\xi$, relating plume centerline temperature with centerline velocity was postulated to be a constant and confirmed with a number of experiments [8]:

$\xi=\left(\mathrm{T}_{\mathrm{a}}^{2 / 5} \mathrm{c}_{\mathrm{p}}^{1 / 5} \rho_{\mathrm{a}}^{1 / 5} / \mathrm{g}^{2 / 5}\right) \mathrm{w}_{\mathrm{c}} /\left(\Delta \mathrm{T}_{\mathrm{c}} \mathrm{Q}_{\mathrm{c}}\right)^{1 / 5}$.

The value of $\xi$ for this series of fire tests was determined to be 1.83 . With the value of $\xi$ determined, the constant $B$ of Eq. (2) was determined from Eq. (4) and $B=3.1$.

A convenient expression for plume width (radius to the point where mean velocity is one-half the centerline value) was derived by Heskestad [8]. For the undeflected plume at the ceiling level, the expression for plume width is

$b_{c}=\left\{2 \pi C \xi\left(C_{p_{a}}\right)^{4 / 5} T_{a}^{3 / 5} g^{2 / 5}\right\}^{-1 / 2} T_{c}^{1 / 2} Q_{c}^{2 / 5} \Delta T_{c}^{-3 / 5}$

where the brackets contain variables of the environment; $C$ and $\xi$ are nondimensional constants: $C=0.29[8]$ and $\xi=1.83$.

\section{Ceiling Gas Flow}

We correlated the near-maximum excess temperatures, $\Delta \mathrm{T}_{\mathrm{p}}$, and velocities, $u_{m}$, in the ceiling gas flow against the radii from the ceiling center in the same fashion proposed by Heskestad [3], i.e. $\Delta \mathrm{T}_{\mathrm{m}} / \Delta \mathrm{T}_{\mathrm{c}}=\mathrm{f}\left(\mathrm{r} / \mathrm{b}_{\mathrm{c}}\right)$ and $u_{\mathrm{m}} / \mathrm{w}_{\mathrm{c}}=$ $g\left(r / b_{c}\right)$

The temperatures and velocities to be correlated were measured at four stations along the east-west run passing through the ceiling center and having the same slope as the ceiling, which is the steepest run along the ceiling. The temperature profile measured at each station indicated that 
the temperature gradient at $13 \mathrm{~mm}$ from the ceiling was close to zero. It appeared that the near-maximum temperature could be assumed to occur at 13 $\mathrm{mm}$ from the ceiling and the temperature profile could be fitted with half of a Gaussian distribution. With regard to the near-maximum gas velocity, we also assumed that it occurred at $13 \mathrm{~mm}$ from the ceiling. However, the gas velocity was only measured at $38 \mathrm{~mm}$ from the ceiling at each station. In order to derive the near-maximum velocity from the measured velocity, both the velocity profile and the excess temperature profile were assumed to follow half of a Gaussian distribution with their maximum values occurring at $13 \mathrm{~mm}$ from the ceiling, and the velocity profile depth, $\delta$, was assumed to be related to the temperature profile depth, $\delta_{\mathrm{T}}$, by $\delta_{\mathrm{V}}=0.85 \delta_{\mathrm{T}}$, based on Yu's experiments [9] on ceiling gas flow under a horizontal ceiling $\left(\delta_{\mathrm{V}}=\right.$ $\left.(0.7 \sim 1) \delta_{\mathrm{T}}\right)$. The profile depth is defined as the depth where the value of the profile has decreased to 0.37 of its maximum value.

For flow under a horizontal ceiling ( $0^{\circ}$ slope), the nondimensionalized near-maximum excess temperature and velocity were plotted against the nondimensionalized radius in Figure $2 a$. The data were fitted with the following formulas:

$\Delta \mathrm{T}_{\mathrm{m}} / \Delta \mathrm{T}_{\mathrm{c}}=\exp \left[-0.42\left(\mathrm{r} / \mathrm{b}_{\mathrm{c}}-1\right)^{0.7}\right\}$ for $\mathrm{r} / \mathrm{b}_{\mathrm{c}} \geq 1$ and $\theta=0$

$u_{m} / w_{c}=\exp \left\{-0.52\left(r / b_{c}-1\right)^{0.6}\right\}$ for $r / b_{c} \geq 1$ and $\theta=0$

The curve fits of kung et al [4] for ceiling flows of growing rack storage fires are also presented in Figure 2a. Their temperature correlation was quite close to the present temperature correlation, but their velocity correlation was consistently higher than the present correlation. It appeared that detailed measurements of velocity profiles are needed in this study in order to determine the near maximum velocity more accurately.

For flows under the $10^{\circ}, 20^{\circ}$ and $30^{\circ}$ slope ceilings, the nondimensionalized near-maximum excess temperatures along the east-west run were plotted against their corresponding nondimensionalized radii in Eigures $2 b, 2 c$ and $2 d$, respectively. The near-maximum excess temperatures in the eastward direction (upward direction) were fitted with the following formula:

$\Delta \mathrm{T}_{\mathrm{m}} / \Delta \mathrm{T}_{\mathrm{c}}=\exp \left\{(0.12 \sin \theta-0.42)\left(\mathrm{r} / \mathrm{b}_{\mathrm{c}}-1\right)^{0.7}\right\}$ for $\mathrm{r} / \mathrm{b}_{\mathrm{c}} \geq 1$ and $\theta=0-30^{\circ}$.

The rates of gas temperature approaching ambient temperature in the east (upward) direction under sloped ceilings were slower than that under a horizontal ceiling. However, the rates of temperature decrease with the radius appeared to be insensitive to the celling slope for the three slopes investigated: $\theta=10,20$ and $30^{\circ}$. The component of the buoyancy force of ceiling gases along the ceiling was in the same direction as the eastward ceiling gas flow and increased with ceiling slope. This component acted on the ceiling gases to accelerate the flow. But the component of the buoyancy force perpendicular to the ceiling decreased as the ceiling slope increased, which would inhibit entrainment of ambient air into the ceiling gases. Entrainment of ambient air is a major mechanism in decreasing the ceiling gas temperature. For ceiling slope from 10 to $30^{\circ}$, the effects of the two components of the buoyancy force on celling gas temperature appeared to compensate each other, so that the decrease of gas temperature with radius was not significantly affected by change of ceiling slope.

In the westward (downward) direction, the component of the buoyancy force along the ceiling was in opposite direction to the ceiling flow. At a certain distance from the ceiling centerline, the ceiling flow separated 
from the ceiling, turning upward. The temperature data in the downward ceiling flow were correlated with the following linear function:

$$
\begin{aligned}
& \Delta \mathrm{T}_{\mathrm{m}} / \Delta \mathrm{T}_{\mathrm{c}}=(0.15 \sin \theta+0.11)\left(\mathrm{r} / \mathrm{b}_{\mathrm{c}}\right)+0.97-0.06 \sin \theta \\
& \text { for } \Delta \mathrm{T}_{\mathrm{m}} \geq 0, \theta=10-30^{\circ} \text { and } \mathrm{r} / \mathrm{b}_{\mathrm{c}}<0 .
\end{aligned}
$$

As provided by Eq. (9), the near-maximum excess temperature reached zero at $\mathrm{r} / \mathrm{b}_{\mathrm{c}}=6.9,5.9$ and 4.9 from the ceiling centerline for $10^{\circ} \mathrm{m}, 20^{\circ}$ - and $30^{\circ} \mathrm{-}$ slope ceilings, respectively. The greater the ceiling slope, the shorter the distance at which the celling gas temperature reached ambient temperature.

The respective plots of the near-maximum ceiling gas velocity versus radius for $10^{\circ}, 20^{\circ}$ and $30^{\circ}$ ceiling slopes are also shown in Figures $2 \mathrm{~b}, 2 \mathrm{c}$, and $2 \mathrm{~d}$. The velocity data in the eastward direction are fitted with the following formula:

$u_{m} / w_{c}=\exp \left\{(0.79 \sin \theta-0.52)\left(r / b_{c}-1\right)^{0.6}\right\}$ for $r / b_{c} \geq 1$ and $\theta=0-30^{\circ}(10)$

Figures $2 b, 2 c$, and $2 d$ indicate that the ceiling slope had a significant effect on the decrease of gas velocity with radius. As the ceiling slope increased, the rate of velocity decrease with radius became smaller. The component of the buoyancy force along the ceiling accelerated the gas flow, thus slowed down the decrease of gas velocity due to entrainment of ambient air.

In the westward ceiling flow, as the gases moved from the ceiling centerline, the gas velocity first decreased to zero, then became negative (flowed in the east direction), and again approached zero. Only the positive velocity data were fitted with the following linear function:

$$
\begin{aligned}
& u_{m} / w_{c}=(0.21 \sin \theta+0.10)\left(r / b_{c}\right)+0.99-1.17 \sin \theta \\
& \text { for } u_{m} \geq 0, \theta=10-30^{\circ} \text { and } r / b_{c}<0 .
\end{aligned}
$$

The nondimensionalized distance, $r / b$ from the ceiling centerline at which the gas velocity first reached zero is called the penetration distance. The penetration distance decreased as the ceiling slope increased. As provided by Eq. (11), the penetration distances were 5.6, 3.5 and 2.0 for $10^{\circ}, 20^{\circ}$ and $30^{\circ}$ ceiling slopes, respectively.

For growing fires, for which the quasi-steady approximation can be applied, the correlations established in this study can be used to obtain the near-maximum ceiling gas temperature and velocity along the steepest run. The quasi-steady approximation implies that the flow at a point under the ceiling may be expected to closely approximate the steady-state flow for the steady-state heat release rate which matches the instantaneous rate. From the instantaneous convective heat release rate of a growing fire, the centerline excess temperature, $\Delta T$, the centeriline velocity, $w_{c}$, and the plume width, $b_{c}$, of the undeflected plume at a given ceiling level can be determined, using Eqs. (1), (2) and (5). With the values for $\Delta \mathrm{T}_{\mathrm{c}}, \mathrm{w}_{\mathrm{c}}$ determined, the near-maximum ceiling gas temperature and velocity at a certain radius from the ceiling centerline along the steepest run can be obtained from Eqs. (6) to (11). 


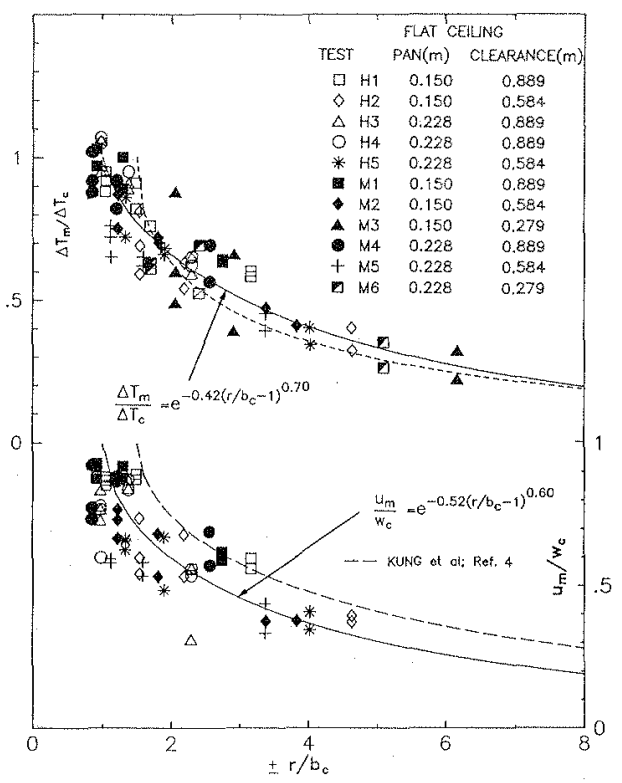

(a) $0^{\circ}$ Ceiling Slope

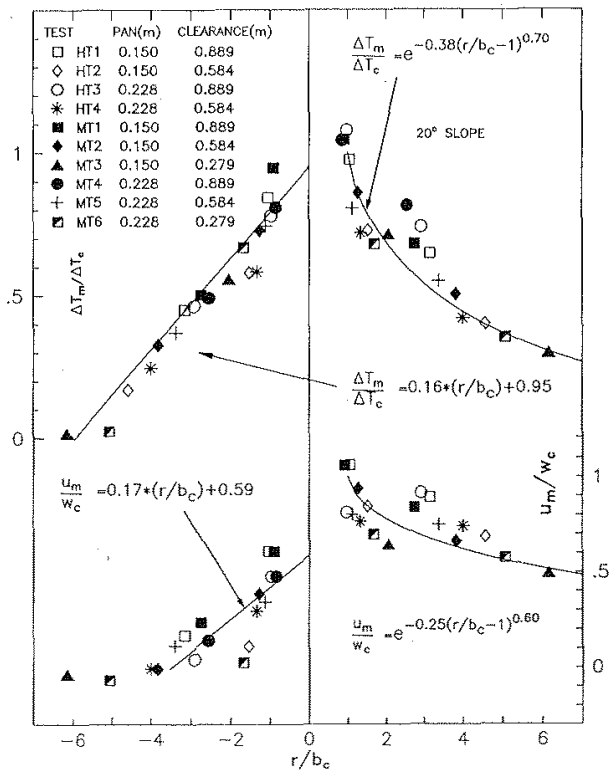

(c) $20^{\circ}$ Ceiling Slope

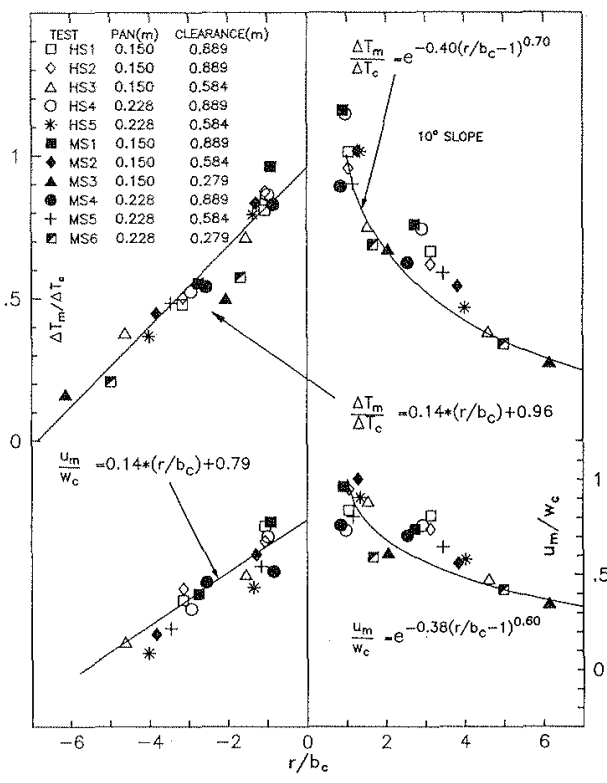

(b) $10^{\circ}$ Ceiling Slope

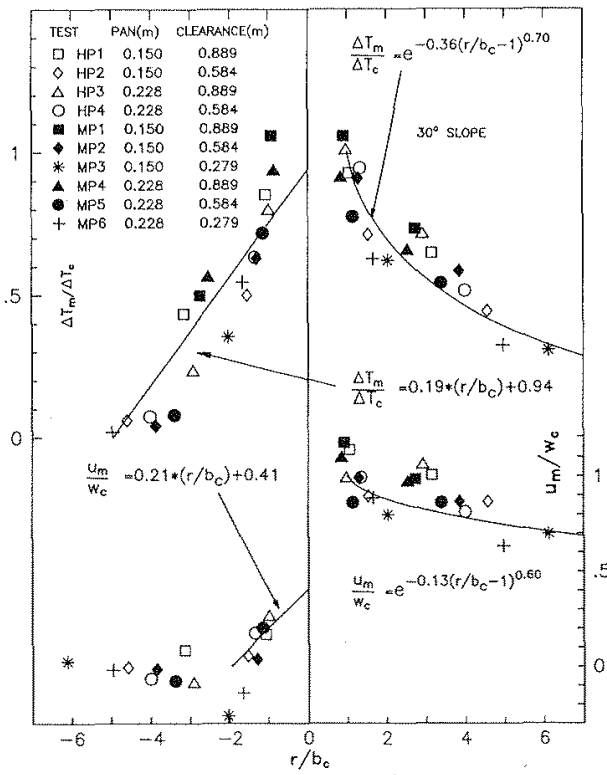

(d) $30^{\circ}$ Ceiling Slope

Figure 2. Near-maximum ceiling gas temperature and velocity versus radial distance from ceiling centerline along the steepest run. 


\section{CONCLUSION}

Empirical correlations for the near-maximum gas velocity and excess temperature of the ceiling flow along the steepest run under a sloped ceiling have been established in terms of celling slope, radius from the celling centerline, and characteristics of the undeflected plume at the ceiling level.

The effect of celling slope on near-maximum gas temperature and velocity along this run has been investigated. In the upward direction, the ceiling slope had a more pronounced effect on velocity variation with radius than on temperature variation. The rate of velocity decrease was reduced significantly as the ceiling slope increased.

In the downward direction, the buoyancy component along the ceiling acted on the ceiling gases to decelerate the flow. At a certain distance (the penetration distance) from the ceiling center the gas velocity decreased to zero, then became negative, and again approached zero. The larger the ceiling slope, the smaller the penetration distance. Furthermore, the distance at which gas temperature approached ambient temperature in the downward direction decreased as the ceiling slope increased.

The correlations established in this study can be used to obtain nearmaximum ceiling gas velocity and temperature for prediction of response of sprinklers and detectors located on the steepest run under a large unconfined ceiling. It is expected that sprinklers located outside the penetration distance on the steepest run in the downward direction would not respond to the fire. In a confined space, the accumulated smoke layer may significantly affect the response of sprinklers and detectors.

\section{REFERENCES}

1. Heskestad, G., "Similarity Relations for the Initial Convective Flow Generated by Fire," ASME Paper 72-WA/HT-17, 1972.

2. Heskestad, G. and Delichatsios, M.A... "The Initial Convective Flow in Fire," 17th Symposium (Intl.) on Combustion, p. 1113, The Combustion Institute, 1978 .

3. Heskestad, G. and Hamada, T., "Ceiling Flows of Strong Fire Plumes," Factory Mutual Research Corporation Tech. Report, J.I. OKOE1.RU, 1984.

4. Kung, H.C., Yu, H.Z and Spaulding, R.D., "Ceiling Flows of Growing Rack Storage Fires," 21st Symposium (Intl.) on Combustion, p. 121, The Combustion Institute, 1986.

5. Heskestad, G., "Bidirectional Flow Tube for Eire-Induced Vent Elows," Factory Mutual Research Corporation, Tech. Report RC74-T-31, Appendix $K$, 1974.

6. Tewarson, A., "Generation of Heat and Chemical Compounds in Fires," Factory Mutual Research Corporation Tech. Report J.I. ON1E1.RC, 1987.

7. Kung, H.C. and Stavrianidis, P., "Buoyant Plumes of Large-Scale Pool Fires," 19th Symposium (Int'l.) on Combustion, p. 905, The Combustion Institute, 1982.

8. Heskestad, G., "Peak Gas Velocities and Flame Heights of BuoyancyControlled Turbulent Diffusion Flames," 18th Symposium (Int1.) on Combustion, p. 951 , The Combustion Institute, 1981.

9. Yu, H.Z. and Stavrianidis, P., "The Transient Ceiling Flows of Growing Rack Storage Fires," Factory Mutual Research Corporation Tech. Report J.I. ON1JO.RA(3), 1989. 